\title{
Cold tack of urea formaldehyde resins as an important factor in plywood production
}

\author{
Elfriede M. Hogger ${ }^{1} \cdot$ Hendrikus W. G. van Herwijnen ${ }^{1} \cdot$ Johann Moser $^{2} \cdot$ Wolfgang Kantner $^{2} \cdot$ Johannes Konnerth $^{3}$
}

Received: 19 January 2018 / Published online: 20 July 2018

(c) The Author(s) 2018

\begin{abstract}
The ability of urea formaldehyde (UF) resins to develop cold tack is needed in plywood production during pre-pressing in a cold press to ensure that the veneers stick together, can be transported, and fit into a multi-daylight hot press. The influence of defined factors on the cold tack was analyzed by determining the tensile shear strength of uncured birch veneers bonded with UF resin, and the statistically significant impact factors were determined. The factors tested were lay-up time, resin amount, resin age, moisture content, veneer temperature and pre-press time. Moisture content and veneer temperature had the highest impact on the cold tack of UF resins. A negative impact of high moisture content on the tensile shear strength and therefore on the cold tack of UF resins was proven as well as a positive impact of a comparably high $\left(30{ }^{\circ} \mathrm{C}\right)$ veneer temperature. Lay-up time and pre-press time showed a minor impact on the tensile shear strength. Models were created using Design-Expert software to calculate the optimum operation conditions for cold tack.
\end{abstract}

\section{Introduction}

It is common practice to pre-press plywood panels in a cold press to activate the cold tack of the resin (Paulitsch and Barbu 2015) before transferring the veneer stack into a multi-daylight hot press. This procedure and the cold tack of the adhesive are necessary for the veneers to stick together after the resin mix was applied. Sufficient cold tack is essential for the step of feeding the hot-press, particularly in plywood panel production, where the glued veneer layers have to stick together to fit into the individual openings of the press (Dunky 1998). To ensure the intimate contact of the single veneers within a panel lay-up, the cold tack of the resin has to fulfill certain requirements.

Different binder types are used in the plywood production depending on the desired material properties. Phenol formaldehyde (PF) resins belong to the group of phenoplastic binders and are appreciated for their high water and weathering

Elfriede M. Hogger

e.hogger@kplus-wood.at

1 Wood K plus - Kompetenzzentrum Holz GmbH, Altenberger Straße 69, 4040 Linz, Austria

2 Metadynea Austria GmbH, Hafenstraße 77, 3500 Krems, Austria

3 University of Natural Resources and Applied Life Science, Gregor-Mendel-Straße 33, 1180 Vienna, Austria resistance. Urea formaldehyde (UF) resins belong to the group of aminoplastic binders most important to wood industry (Dunky and Niemz 2002). Unmodified UF resin is applied when the final product is used for interior purposes with limited water resistance. UF resins are also described as being easy to handle, low priced and widely available. Moreover, they ensure a high strength of the bond under dry conditions. Another benefit of UF is the possibility of cold tack (Dunky 1998; Dunky and Niemz 2002), which is the focus of the present study.

Tack of a resin is defined as the property to form a bond immediately when in contact with another surface (EN923 2005), and is usually referred to as cold tack, as this occurs without the addition of temperature (Dunky and Niemz 2002). Dunky (1998) described the mechanism of tack formation by drying of a bondline, whereby a certain stage of drying must not be exceeded. The cold tack of UF is assumed to be influenced by various adhesive related factors such as resin synthesis procedure, adhesive age, addition of additives, or the open assembly time (Dunky and Niemz 2002) as well as by adherent related factors such as wood species, moisture content, and surface age.

Dunky and Niemz (2002) described the cold tack of a UF resin to depend on its molar ratio $\mathrm{F} / \mathrm{U}$. A higher cold tack can therefore be achieved by using specific resin cooking procedures or by the addition of additives to the resin. They state that the drying behavior of the resin applied to the surface of 
a panel is a key factor for the development of cold tack with UF resins. This drying behavior is time dependent, shows a maximum after a certain time, and leads to a reduction in cold tack when this maximum has been exceeded.

Various investigations were carried out with regard to cold tack of UF with an emphasis on particleboard production. Cold tack can be classified as desired (for the stabilization of the particle mat prior to hot pressing) as well as unintentionally or even not wanted, when causing sticking onto machinery parts (Gierlinska and Starzynska 1986; Himsel et al. 2015, 2016). Gierlinska and Starzynska (1986) focused on the resin formulation and therefore the molar ratio of the UF resin as a precondition to develop cold tack; Himsel et al. $(2015,2016)$ showed how the sticking behavior of melamine urea formaldehyde (MUF) resins and ultra-lowemitting formaldehyde (ULEF) resin changes depending on ambient conditions. Resin age, temperature and humidity of the surrounding area were identified as main influencing factors of sticking.

Neumann and Müller (1979) identified influencing factors by dividing them into adhesion and cohesion related factors. They tested the adhesion factors by using different particleboard resin mixtures and defined moisture content, test conditions, open time, press time, pressure, resin amount, and tension speed when tearing scarf joints according to DIN53253 (1964) (Walter 1977) as cohesion factors. As one important result, moisture content and temperature were identified to have a great influence on the tensile shear strength.

Although cold tack behavior was identified to be of importance, information on systematic investigation of cold tack behavior for plywood production is scarce. In the present study, it was aimed for a better understanding of the cold tack of UF for plywood production. The drying behavior of the resin is a key factor for cold tack, which is supposed to be influenced by various factors. Therefore, the focus of this study was on the systematic investigation of its potentially influencing factors, such as lay-up time, resin amount, resin age, moisture content, veneer temperature, and pre-press time. A better understanding of the change in cold tack with these factors will contribute to a better control of this step in the plywood production. In contrast to other studies where performance of the cured bond was in focus, the cold tack is assessed by monitoring the behavior of the resin in the still uncured state. Therefore, it was necessary to develop a suitable method allowing examining the influence of the defined factors on the cold tack. In these experiments, tensile shear strength was used to test the cold tack behavior of the resin.

\section{Materials and methods}

\subsection{Materials}

Rotary cut sheets of birch (Betula) veneer with dimensions of $500 \times 500 \mathrm{~mm}^{2}$ and a thickness of $1.5 \mathrm{~mm}$ were stored in standard climate $\left(20{ }^{\circ} \mathrm{C}, 65 \%\right.$ r.h. $)$ prior to the experiments. An industrial UF resin, fulfilling requirements for formaldehyde emission class E1, with a density of $1.25 \mathrm{~g} / \mathrm{cm}^{3}$, solid content of $63 \%( \pm 3 \%)$ and viscosity of $500 \mathrm{mPa}$ s was provided by Metadynea Austria GmbH (Krems, Austria). $1.75 \%$ (liquid hardener on liquid resin) of a $20 \%$ aqueous ammonium chloride solution was added to the resin as a hardener (provided by Metadynea Austria $\mathrm{GmbH}$, Krems, Austria).

\subsection{Testing parameters}

Six factors with three orthogonal levels were defined (Table 1). The selected levels are based on industrial conditions and contain possible low and high realistic levels. Lay-up times of 10-35 min are just as common in production plants as the selected resin amount levels. The storage stability of the resin specified by the manufacturer is about 3 weeks. Therefore, a resin age of 1 week for resin 5-7 days after cooking, 2 weeks for resin 12-14 days after cooking and 3 weeks for resin 19-21 days after cooking was defined. The veneer moisture content was selected to cover a range between dry winter climate (4\% MC occurring at e.g. $10{ }^{\circ} \mathrm{C}$ ) and continental summer conditions $\left(12 \% \mathrm{MC}\right.$ at a temperature of e.g. $\left.30^{\circ} \mathrm{C}\right)$. Following preliminary tests of extreme values, a high pre-press time of 45 min was chosen.

The lay-up time was defined as the interval between assembly of the glued surfaces and the start of the prepress time.

Table 1 Selected parameters and their orthogonal levels

\begin{tabular}{lllll}
\hline Parameters $(P)$ & \multicolumn{3}{l}{ Levels $(L)$} \\
\cline { 3 - 5 } & & 1 & 2 & 3 \\
\hline A & Lay-up time (min) & $10-15$ & $20-25$ & $30-35$ \\
B & Resin amount $\left(\mathrm{g} / \mathrm{m}^{2}\right)$ & 90 & 120 & 150 \\
C & Resin age (weeks) & 1 & 2 & 3 \\
D & Veneer moisture content (MC) $(\%)$ & 4 & 8 & 12 \\
E & Veneer temperature $\left({ }^{\circ} \mathrm{C}\right)$ & 10 & 20 & 30 \\
F & Pre-press time (min) & 15 & 30 & 45 \\
\hline
\end{tabular}




\subsection{Experimental design (DoE) and statistical analysis}

Due to the high number of testing factors, a thoroughly planned experimental procedure was essential to optimize experimental efforts. A full factorial design with six factors and three levels would request $729\left(3^{6}\right)$ experimental combinations. By preparing five samples for each experimental combination to account for variable wood properties, a total of 3645 samples would have been needed for such a full factorial test design. A $2^{\mathrm{k}-\mathrm{p}}$ fractional factorial designed experiment, on the other hand, reduces the number of samples to $10 \%$ of the full factorial design, since the maximum and minimum levels were combined; based on this a characterization design of resolution $\mathrm{V}\left(2^{6-1}\right)$ was chosen (Box and Hunter 1961). Two repetitions (using 5 samples per repetition) of the 32 experimental combinations were performed; a center point, which combined all the mean levels, was repeated 10 times (using again 5 samples per repetition). In total 370 samples had to be tested. The tensile shear strengths as results of each experiment were evaluated using the statistical software Design-Expert ${ }^{\circledR}$ (version 10, Stat-Ease, Inc., Minneapolis, USA). The arithmetic mean value was calculated for the five samples for each experimental combination. The responses and corresponding parameters were modelled and analyzed using an analysis of variances (ANOVA); additionally, a multivariate regression model was calculated (Anderson and Whitcomb 2007; Brosius 2002). The response surface method (RSM) generated maps of responses as three-dimensional plots. As a statistical method, RSM uses quantitative data from conducted experiments to determine regression model equations and operating conditions (Sahu et al. 2010).

Direct experimental results were visualized using boxplots and SPSS Software (version 21, Statistical Package for Social Science, IBM ${ }^{\circledR}$, Armonk, USA). Values of experimental combinations with $n=10$ samples and $n=49$ valid samples for the center point were compared.

\subsection{Sample preparation and test setup}

The veneers were cut into strips with dimensions of $170 \times 34$ $\mathrm{mm}^{2}$. An overlapping length (a) of approx. $10 \mathrm{~mm}$ for the adhesive application was determined leading to a resinated overlapping area of approx. $340 \mathrm{~mm}^{2}$ (A) (Fig. 1). The precise overlapping dimensions were determined after testing for each individual lap joint using a clipper.

The following test setup was developed to investigate the cold tack properties of UF resins (Fig. 2).

The veneer moisture content $( \pm 1 \%)$ and veneer temperature were equilibrated using two climate chambers (WTB-Kühlbrutschrank, Binder, Tuttlingen, Germany;

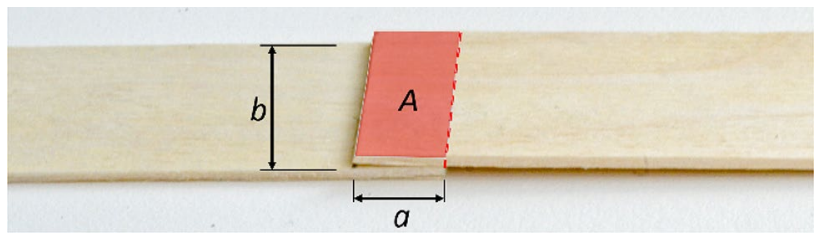

Fig. 1 Veneers for lap joint specimens prior to cold pressing, where $\mathrm{a}=10 \mathrm{~mm}$ and $\mathrm{b}=34 \mathrm{~mm}$, corresponding to a resinated overlapping area of $\mathrm{A}=340 \mathrm{~mm}^{2}$

Temperature and Climatic Test Chamber WK3 180/40, Weiss Technik AG, Altendorf, Switzerland). $120 \mathrm{~g} / \mathrm{m}^{2}$ $\left( \pm 30 \mathrm{~g} / \mathrm{m}^{2}\right)$ of the prepared resin mixture was applied with a spatula to the one strip and distributed evenly on the surface. The second veneer was placed on the overlapping surface without external pressure; then the two assembled veneers were stored in the climate chambers for the intended lay-up time. Following this period, the assemblies were pre-pressed using a manual press with a pressure of $1.5 \mathrm{~N} / \mathrm{mm}^{2}$ exposing the samples to the same controlled climatic conditions as during the preceding step. The samples were subsequently tested in tensile shear mode using a universal testing machine (Zwick/Roell Z020, Ulm, Germany). For measuring the ultimate force, a load cell with a load capacity of $5 \mathrm{kN}$ and a cross-head speed of $0.3 \mathrm{~mm} / \mathrm{min}$ was used, aiming for a test duration of $60 \mathrm{~s}$. Tensile shear strength was calculated by dividing the maximum force by the measured overlapping area.

\section{Results and discussion}

The tensile shear strengths are presented in Fig. 3, visualizing the different factors chosen. As a general trend higher values were measured for the lowest veneer moisture content (Fig. 3a). Additionally, higher shear strength is observed for high veneer temperatures; low veneer temperatures reach $1 \mathrm{~N} / \mathrm{mm}^{2}$ only when combined with low moisture content. The highest tensile shear strength is given for low moisture content, high veneer temperature, high pre-press time and high resin amount; the lowest tensile shear strengths are the consequence of high moisture content and low temperatures (Fig. 3a).

Noticeable in Fig. $3 \mathrm{~b}$ is the higher scattering of the results occurring from the missing differentiation for moisture content and pre-pressing time. Higher tensile shear strength was again observed for high temperature, high resin amount, and a low lay-up time. No obvious change in tensile shear strength with a change in resin age or lay-up time was apparent. 
Fig. 2 Procedure for evaluation of cold tack properties
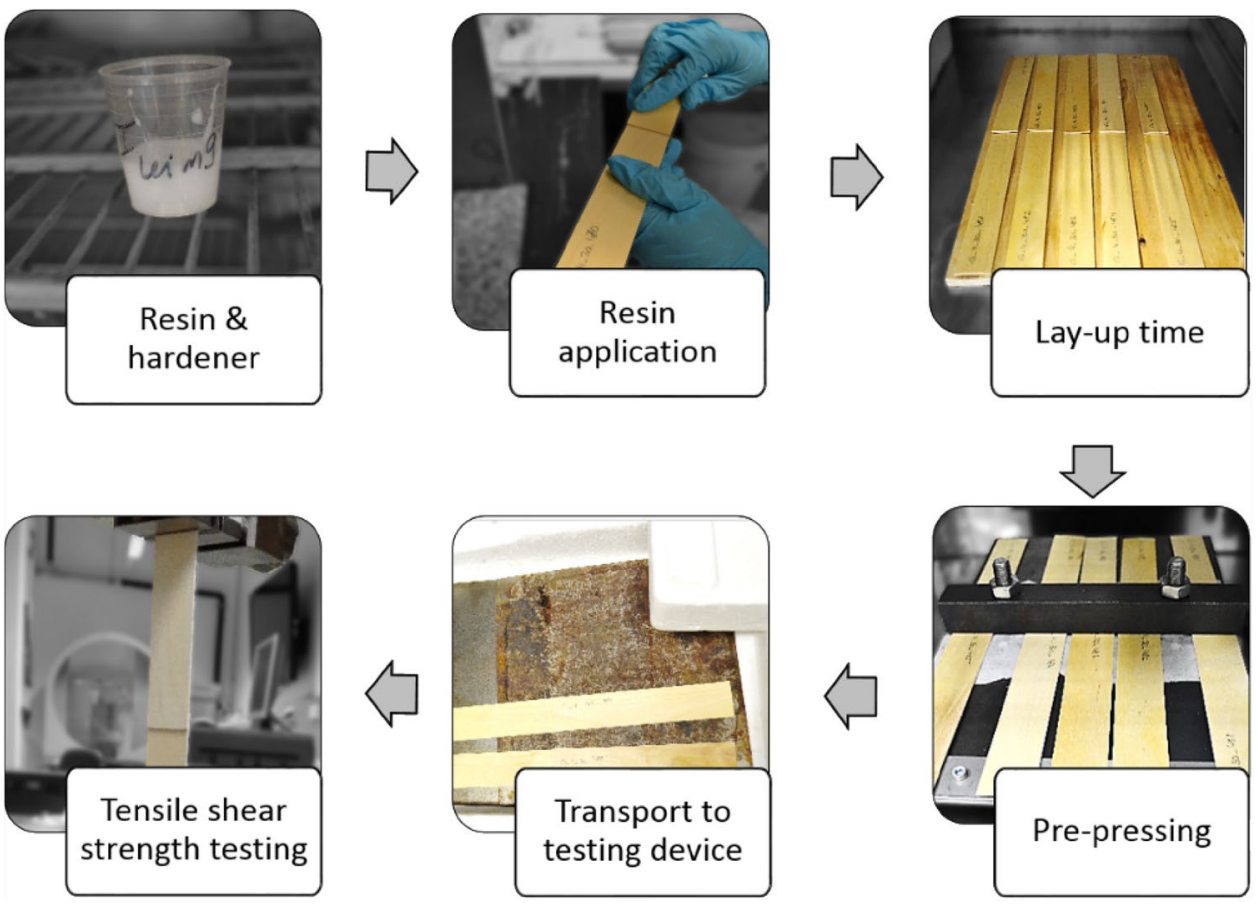

\subsection{Statistical evaluation}

In order to check whether the chosen factors significantly influenced the observed results (Fig. 3) and whether there are interactions between the factors that influence the outcome, statistical evaluations were conducted with the help of an analysis of variances (ANOVA) and a multivariate data analysis. The quality of the ANOVA model was evaluated based on the correlation coefficient $\left(\mathrm{R}^{2}\right)$ value. The calculated $R^{2}$ value was 0.80 , indicating that $80 \%$ of the total variation of the tensile shear strength as an indicator for the cold tack was attributed to the experimental variables studied. Considering the calculated $\mathrm{R}^{2}=0.80$, the model satisfactorily describes the experimental data. The standard deviation estimated in the ANOVA was $0.2 \mathrm{~N} / \mathrm{mm}^{2}$, reflecting typical variability for the inhomogeneous material wood. High $\mathrm{R}^{2}$ values together with low standard deviation stand for the high quality of the model (Fig. 4).

The adequacy of the model was further justified through an F-test with a significance level of 5\%. The probability value (p-value) of the model was highly significant with $\mathrm{p}<0.0001$ (Table 2), which indicated, together with the calculated $\mathrm{R}^{2}$, that the model developed for tensile shear strength prediction exhibited a good fit. A square root transformation was performed, since the data was not normally distributed.

P-values greater than 0.05 indicate that the model terms did not significantly influence the tensile shear strength. The ANOVA performed showed several significant factors, such as lay-up time, moisture content, veneer temperature, and pre-press time. Additionally, interactions between the factors (1) lay-up time and moisture content, (2) resin amount and moisture content, (3) lay-up time, resin amount, and resin age, as well as (4) lay-up time, resin amount, and veneer temperature were marked as significant. Interactions of higher order should be examined with caution, as these effects are difficult to interpret and interactions of three or more terms are assumed not to be significant (Anderson and Whitcomb 2007).

To predict responses for given levels of each factor and for identifying the relative impact of the factors and factor interactions on the response value, the equation in terms of coded factors can be used (Table 2). The factors are coded as +1 for high levels and -1 for low levels (Anderson and Whitcomb 2007). The values calculated thereof are either positive or negative, which indicates whether the factor leads to an increase or decrease in the result. The higher the absolute values, the more influence on the response value is given.

With a value of -0.22 (Table 2), the moisture content has the highest impact on the tensile shear strength, followed by the veneer temperature $(0.20)$. Increasing moisture content negatively affects the tensile shear strength, whereas increasing veneer temperature shows a positive effect. The coded factors indicate increasing tensile shear strength for low moisture content or high temperature. The results fit with results reported by Neumann and Müller (1979), who observed an increase in tensile shear strength when the temperature rises from 20 to $25^{\circ} \mathrm{C}$ when testing cold tack of UF on scarf joints. They attributed the higher cold tack to the 
Fig. 3 Tensile shear strength as the result of cold tack of birch veneer samples: $\mathbf{a}$ in dependence of veneer moisture content, resin amount, pre-press time, and veneer temperature, $\mathbf{b}$ in dependence of resin age, lay-up time, resin amount, and veneer temperature. 10 samples for each experimental combination (49 samples for the center point)
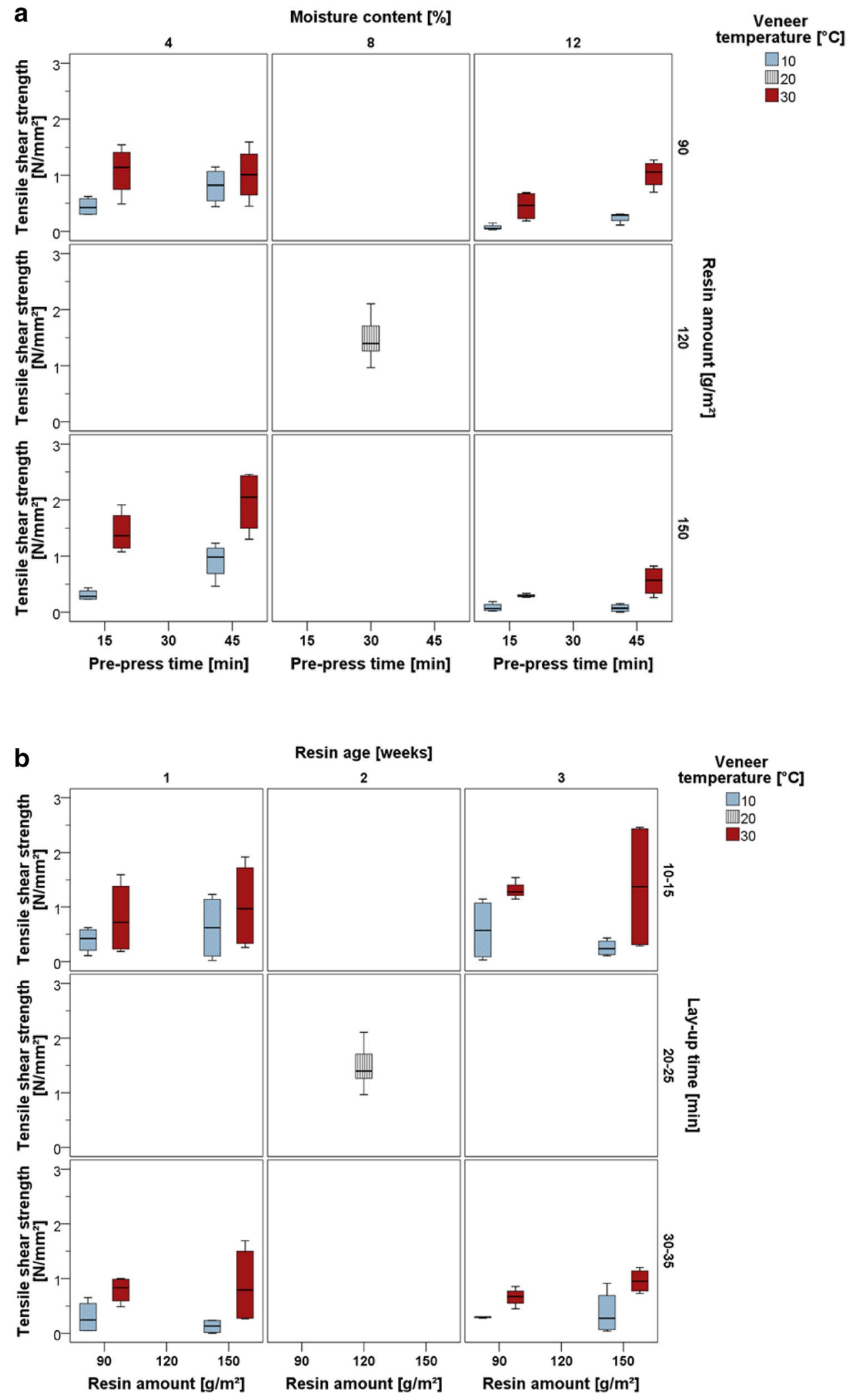

increase in the solid content by the faster water removal at higher temperatures. A slightly negative effect $(-0.064)$ was calculated for the lay-up time, which can be explained by the importance of drying of the resin for the cold tack development; the drying out process, however, may not exceed a certain time, since the cold tack decreases again (Dunky and 


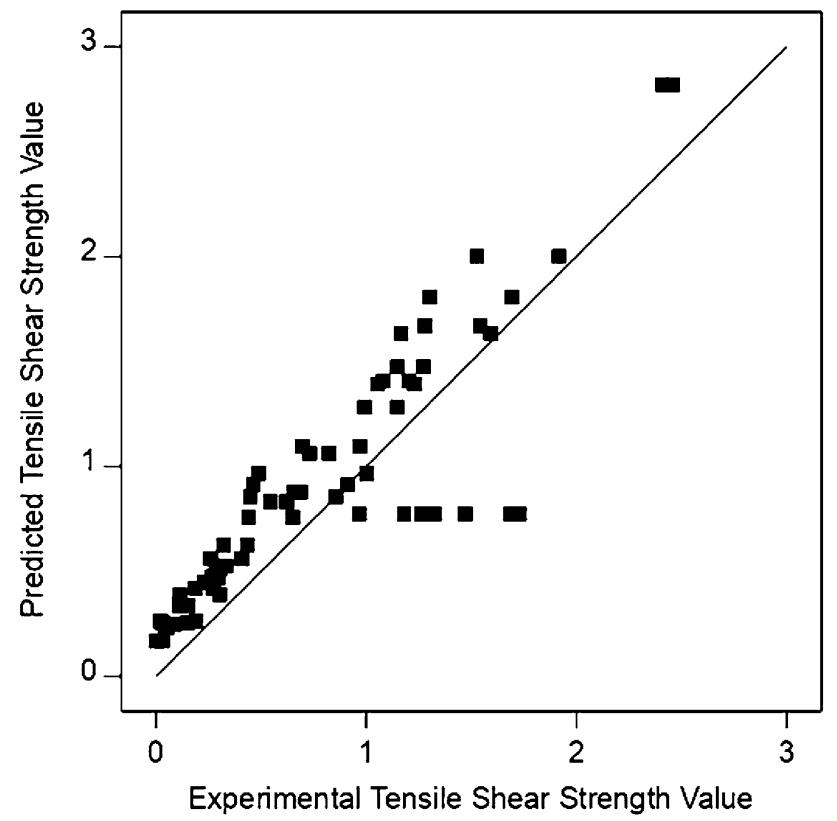

Fig. 4 Predicted tensile shear strength values plotted against the experimentally tested values

Niemz 2002). Even though the resin amount as a main factor showed no significance for the model, the interaction with the moisture content has a minor negative effect $(-0.072)$, which leads to the presumption that a high moisture content and high resin amount decrease the tensile shear strength.

This observation might be explained by the high proportion of water in addition to the high water content in the veneer, with both impeding drying of the adhesive. This behavior is indicated in Fig. $3 \mathrm{a}$ and can be explained through the statistic evaluation, since the interaction of the factor moisture content and resin amount was identified to be significant in the model. The fact that the resin age was characterized as a non-significant factor is also reflected in the coded factors and is implied in Fig. 3b. The aging of the adhesive is usually accompanied by an increase in viscosity. The fact that the age of the resin does not influence the cold tack can be compared with the statements of Neumann and Müller (1979) that viscosity alone is not decisive for the measured value. Adhesives with the same viscosities, produced under different condensation conditions showed different cold tack values, while aged, noncold tacky adhesive resins with high viscosities showed no noticeable increase in cold tack. Himsel et al. (2015) detected a decrease in sticking behavior of an ULEF resin together with increasing viscosity, both as a result of adhesive ageing within 21 days.

In the present study, a resin of emission class E1 was used and no significant influence of the resin age on the cold tack was measurable within 21 days after production of the resin. A positive impact (+0.095) of the pre-press time was calculated and agrees with Dunky and Niemz (2002), who described the increase in cold tack in precompressed particle mats by a higher pre-press time. The two-factorial interaction between lay-up time and moisture content has a low positive coefficient $(+0.073)$, which means the negative effect of moisture content is slightly reduced as the lay-up time increases, which again

Table 2 Analysis of variances (ANOVA) showing the main factors and interactions at significance level of 5\%

\begin{tabular}{|c|c|c|c|c|c|c|c|}
\hline Source & Sum of squares & $\begin{array}{l}\text { Degree of } \\
\text { freedom }\end{array}$ & Mean square & F-value & $\begin{array}{l}\mathrm{p} \text {-value } \\
\text { Prob }>\mathrm{F}\end{array}$ & & $\begin{array}{l}\text { Final equation in } \\
\text { terms of coded } \\
\text { factors }\end{array}$ \\
\hline Model & 8.06 & 22 & 0.37 & 9.17 & $<0.0001$ & Significant & +0.79 \\
\hline Lay-up time & 0.26 & 1 & 0.26 & 6.47 & 0.0141 & Significant & -0.064 \\
\hline Resin age & 0.10 & 1 & 0.010 & 2.56 & 0.1161 & & +0.040 \\
\hline Moisture content (MC) & 2.99 & 1 & 2.99 & 74.79 & $<0.0001$ & Significant & -0.22 \\
\hline Veneer temperature & 2.62 & 1 & 2.62 & 65.49 & $<0.0001$ & Significant & +0.20 \\
\hline Pre-press time & 0.58 & 1 & 0.58 & 14.56 & 0.0004 & Significant & +0.095 \\
\hline Lay-up time $\times M C$ & 0.34 & 1 & 0.34 & 8.51 & 0.0053 & Significant & +0.073 \\
\hline Resin amount $\times M C$ & 0.34 & 1 & 0.34 & 8.51 & 0.0053 & Significant & -0.072 \\
\hline $\begin{array}{l}\text { Lay-up time } \times \text { resin } \\
\text { amount } \times \text { resin age }\end{array}$ & 0.16 & 1 & 0.16 & 4.05 & 0.0496 & Significant & +0.050 \\
\hline $\begin{array}{l}\text { Lay-up time } \times \text { resin } \\
\text { amount } \times \text { veneer tem- } \\
\text { perature }\end{array}$ & 0.18 & 1 & 0.18 & 4.75 & 0.0374 & Significant & -0.053 \\
\hline Residual & 2.00 & 50 & 0.040 & - & - & & \\
\hline Lack of fit & 1.57 & 10 & 0.16 & 14.66 & $<0.0001$ & Significant & \\
\hline Pure error & 0.43 & 40 & 0.010 & - & - & & \\
\hline Cor total & 10.06 & 72 & - & - & - & & \\
\hline
\end{tabular}


relates to the drying behavior of the resin. Other interactions did not show to have significant influence on the final results.

Figure 5 presents the graphical plots of the mathematical model using the example of (1) highest and lowest resin amount and lowest moisture content combined with the highest temperature (top) and (2) the highest moisture content combined with the lowest temperature (bottom), all for a resin age of 2 weeks. The 3D plots illustrate the previously calculated statistical effects of the factors and their interactions on the tensile shear strength. The highest tensile shear strengths can be reached when using the following conditions: a low veneer moisture content, a high resin amount $\left(150 \mathrm{~g} / \mathrm{m}^{2}\right)$, a lay-up time of $10 \mathrm{~min}$ and a pre-press time of $45 \mathrm{~min}$ (Fig. 5, top right). While an increase of the resin amount for dry veneers (low moisture content) at high temperature leads to higher tensile shear strength, the opposite development can be observed when high moisture content is combined with low temperatures. Again, this observation emphasizes the importance of the drying behavior for the resin to build up cold tack (Dunky and Niemz 2002) as explained above, since high moisture, high resin amount, and low temperature hinder the drying process. The model obtained can now be used to determine and visualize which levels of a factor lead to critical cold tack in order to avoid them in the plywood panel production process.

\section{Conclusion}

Cold tack is an important property of the resin used in plywood production. In the work reported here, the cold tack behavior of a UF resin could be successfully evaluated by measuring the shear strength of a single lap shear specimen prior to the curing of the resin; this allowed observing various influencing factors (e.g. veneer moisture content and veneer temperature) from sample preparation to strength determination. The developed test setup can be used for further investigations on the behavior of cold tack and can be extended to further possible influencing factors.

Based on the results of this study it was proven that the lay-up time, veneer moisture content, veneer temperature, and the pre-press time, together with the interaction of (1) lay-up time and moisture content as well as (2) resin amount and moisture content, had a significant impact on the tensile shear strength and thus, the cold tack of the investigated UF resin mix. The strongest influence on cold tack was shown to be the moisture content, where high levels lead to low tensile shear strength, followed by the veneer temperature, which results in a high tensile shear strength when increased. The lay-up time, moisture content, and the twofactorial interaction of resin amount with moisture content negatively influenced the tensile shear strength; in contrast higher veneer temperature, longer pre-press time, and the two-factorial interaction between lay-up time and moisture content increased the shear strength.
Fig. 5 3D model plots of the tensile shear strength as a result of cold tack for different veneer conditions (MC veneer moisture content, $\mathrm{T}$ veneer temperature) and resin amounts at a resin age of 2 weeks

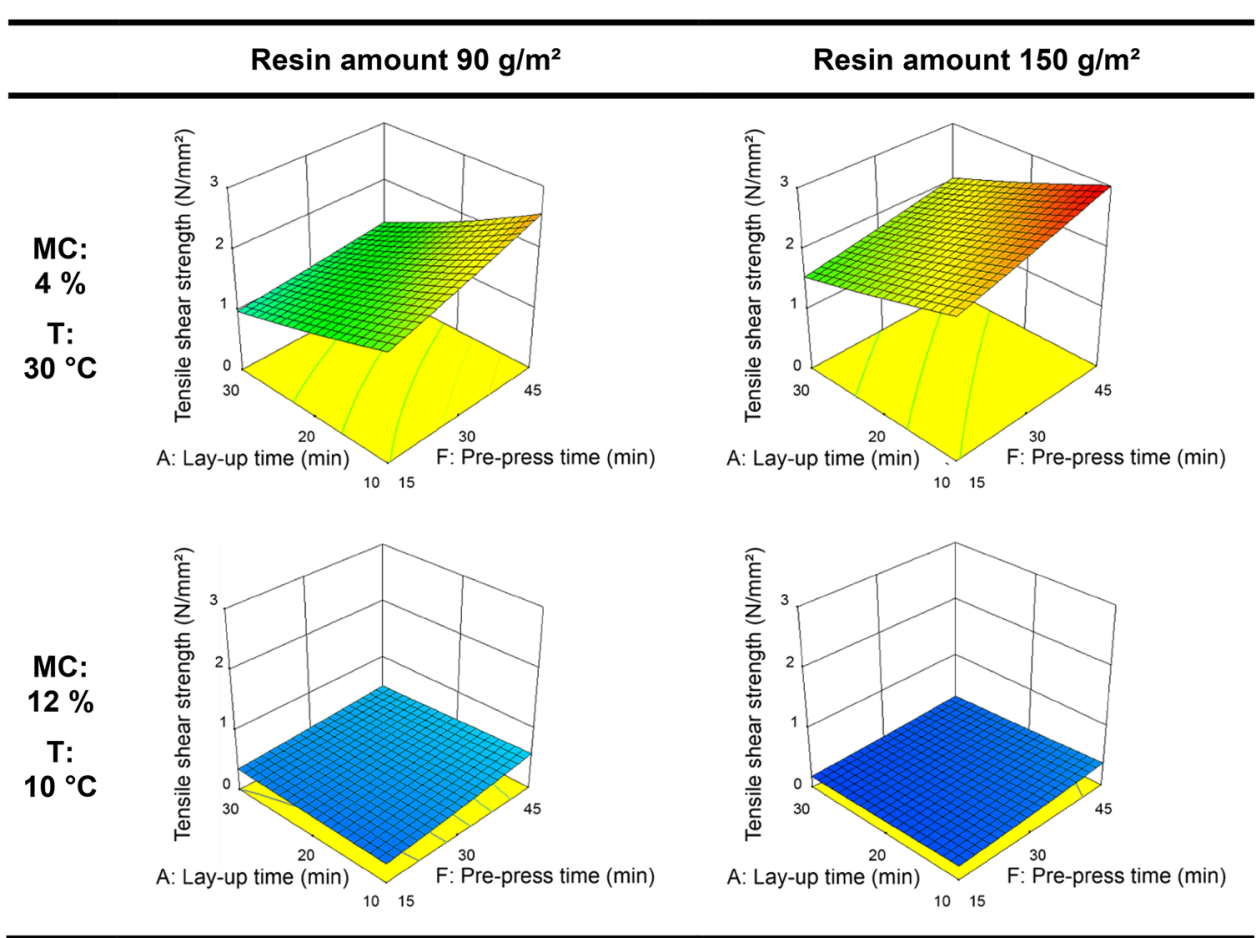


The results of this study can be used to adapt and optimize individual factors to achieve the best cold tack at respective situations and avoid additional handling during the production process.

The effect of the used settings on the adhesive curing and consequently on the final plywood quality will be investigated in a further study.

Acknowledgements Open access funding provided by University of Natural Resources and Life Sciences Vienna (BOKU). The authors gratefully acknowledge the financial support of the Austrian Research Promotion Agency FFG within the COMET program. Funding was provided by Österreichische Forschungsförderungsgesellschaft (Grant no: 844608$)$.

Open Access This article is distributed under the terms of the Creative Commons Attribution 4.0 International License (http://creativeco mmons.org/licenses/by/4.0/), which permits unrestricted use, distribution, and reproduction in any medium, provided you give appropriate credit to the original author(s) and the source, provide a link to the Creative Commons license, and indicate if changes were made.

\section{References}

Anderson MJ, Whitcomb PJ (2007) DOE Simplified: practical tools for effective experimentation, 2nd edn. Taylor \& Francis Group, Florida

Box GEP, Hunter JS (1961) The $2^{\mathrm{k}-\mathrm{p}}$ fractional factorial desings-part I. Technometrics 3:311-351. https://doi.org/10.2307/1266725

Brosius F (2002) SPSS 11. mitp verlag. Landsberg, Paderborn, Bonn

DIN53253 (1964) Testing of adhesives and glued wood joints-tensile test for determining the failing strength of scarf joints. Deutsches Institut für Normung e.V, Berlin

Dunky M (1998) Urea-formaldehyde (UF) adhesive resins for wood. Int J Adhes Adhes 18:95-107. https://doi.org/10.1016/S0143 -7496(97)00054-7
Dunky M, Niemz P (2002) 1 Formaldehyd-Kondensationsharze (1 Formaldehyde-condensation resins). In: Holzwerkstoffe und LeimeTechnologie und Einflußfaktoren. Springer, Berlin (in German)

EN923 (2005) Adhesives-terms and definitions. European Comittee for Standardization, Brussels

Gierlinska I, Starzynska K (1986) Untersuchung der Kaltklebrigkeit von Harnstoff-Formaldehyd-Harzen aus konzentriertem Formaldehyd (Investigation of the cold tack of urea-formaldehyde resins from concentrated formaldehyde). Holztechnologie 27:149-154 (in German)

Himsel A, Moser J, Kantner W, Mitter R, Gießwein J, van Herwijnen HWG, Müller U (2015) Describing the sticking phenomenon of aminoplastic resins: introduction of a new test method. Wood Sci Technol 49:681-694. https://doi.org/10.1007/s00226-015-0724-x

Himsel A, van Herwijnen HWG, Moser J, Kantner W, Mitter R, Gießwein J, Müller U (2016) Describing the sticking phenomenon of aminoplastic resins: dependency on temperature and relative humidity. Eur J Wood Prod 74:31-36. https://doi.org/10.1007/ s00107-015-0990-1

Neumann R, Müller V (1979) Untersuchungen zur Ermittlung der Kaltklebekraft von Harnstoff-Formaldehyd-Harzleimen (Investigations to determine the cold tack of urea-formaldehyde resins). Holztechnologie 20:99-103 (in German)

Paulitsch M, Barbu MC (2015) Holzwerkstoffe der Moderne (Wood materials of the modern age) (In German). DRW-Verlag Weinbrenner, Leinfelden-Echterdingen

Sahu JN, Acharya J, Meikap BC (2010) Optimization of production conditions for activated carbons from tamarind wood by zinc chloride using response surface methodology. Biores Technol 101:1974-1982. https://doi.org/10.1016/j.biortech.2009.10.031

Walter F (1977) Prüftechnik in der Holzindustrie (Testing technology in the wood industry). VEB Fachbuchverlag, Leipzig (in German)

Publisher's Note Springer Nature remains neutral with regard to jurisdictional claims in published maps and institutional affiliations. 